\title{
Shengmai-san-Mediated Enhancement of Regenerative Responses of Spinal Cord Axons After Injury in Rats
}

\author{
Tae Beom Seo ${ }^{1}$, Kyungmin Baek ${ }^{1}$, Ku-Birm Kwon ${ }^{1}$, Sang-Ik Lee ${ }^{1}$, Jong-Soon Lim ${ }^{1}$, In Chan Seol ${ }^{1}$, \\ Yoon Sik Kim ${ }^{1}$, Young-Bae Seo ${ }^{1}$, and Uk Namgung, ${ }^{1, *}$ \\ ${ }^{1}$ Department of Oriental Medicine, Daejeon University, Daejeon 300-716, Korea
}

Received February 11, 2009: Accepted June 20, 2009

\begin{abstract}
Shengmai-san (SMS) is a traditional Chinese medicine used to treat diverse symptoms including cardiovascular and neurological disorders. Here we investigated the effects of SMS on regenerative responses of spinal cord axons in rats that were given contusion injury at the lower thoracic level. The injury cavity was confined to a restricted area by SMS treatment, and the signals of glial scar protein chondroitin sulphate proteoglycan (CSPG) and inflammatory cell marker protein $\mathrm{CD} 11 \beta$ were heavily observed within the injury cavity in SMS-treated animals. Anterograde tracing of DiI-labeled corticospinal tract (CST) axons revealed increases in collateral arborization around and within the injury cavity and caudal elongation by SMS treatment. Furthermore, SMS treatment facilitated neurite elongation of dorsal root ganglion (DRG) sensory neurons that were co-cultured with non-neuronal cells prepared from injured spinal cord. Phospho-Erk1/2 was strongly induced in both spinal cord and motor cortical areas after spinal cord injury (SCI), and it was further unregulated in the motor cortex by SMS treatment. In contrast, upregulation of cell division cycle 2 ( $\mathrm{Cdc} 2)$ production by SMS treatment was limited to a local, SCI area. These data suggest that SMS may play an active role in regenerative responses and facilitate axonal regrowth after SCI.
\end{abstract}

Keywords: Shengmai-san, spinal cord injury, axonal regeneration, Erk1/2, cell division cycle $2(\mathrm{Cdc} 2)$

\section{Introduction}

While the injured axons in the peripheral nervous system (PNS) have the ability to regenerate and innervate to their original targets, damaged axons in the central nervous system (CNS) generally fail to regenerate and lead to permanent functional deficit in affected body parts. Myelin-associated molecules such as Nogo, myelin-associated glycoprotein (MAG), oligodendrocyte myelin glycoprotein (OMgp), semaphorin 4D (Sema4D/CD), and chondroitin sulphate proteoglycan (CSPG) are a few examples of glial cell proteins interfering with CNS axonal regeneration (1). Besides environmental influences, some CNS neurons do not produce intrinsic, growth-promoting molecules that are inducible from regenerating peripheral neuron after axonal injury.

*Corresponding author. unamgung@dju.ac.kr

Published online in J-STAGE

doi: 10.1254/jphs.09044FP
In this case, molecular supply to injured CNS neurons can induce axonal regeneration. For instance, overexpression of axonal growth-associated protein GAP-43, which was reported to facilitate spontaneous or lesioninduced sprouting of peripheral motor axons to target muscle (2), effectively induced axonal elongation of the central branch of dorsal root ganglion (DRG) sensory neurons after spinal cord injury (SCI) (3). Schwann cell graft or administration of neurotrophic factors such as BDNF, NT-4, and NGF, which are induced in injured peripheral nerve, facilitated axonal regrowth after SCI $(4-8)$. Phosphorylated Erk1/2 protein is increased in regenerating peripheral neurons and also associated with regenerative responses after SCI $(9-12)$. Finally, we have recently demonstrated that cell division cycle 2 $(\mathrm{Cdc} 2)$, a prototypical cyclin-dependent kinase (Cdk) family protein, is involved in peripheral nerve regeneration via promoting Schwann cell migration (13); yet, its function in the injured spinal cord is not known. Thus, molecules favoring axonal regeneration in the PNS can 
be considered for therapeutic strategies to induce axonal growth and functional recovery after SCI.

In Chinese traditional medicine, Shengmai-san (SMS) has been used for treating symptoms related to cardiovascular diseases such as heart failure, stroke, and shock, and recent studies have begun to provide evidence showing that SMS has protective effects against oxidative damages in the cells or tissues of the cardiovascular and nervous systems $(14-16)$. Suggested potential of SMS for neuroprotection and neurite outgrowth further implicates the applicability of SMS for treatment of axon-degenerative diseases such as amyotrphic lateral sclerosis (ALS) in which the deficiency of superoxide dismutase (SOD) is thought to be linked to neuronal damage (17).

Here we investigated whether SMS has a supportive role in axonal growth and cell survival after SCI, which would otherwise undergo axonal die-back and degeneration. Throughout the primary screening procedure of selected herbal decoctions, SMS was identified to induce enhanced axonal regeneration of the injured sciatic nerve in the rat (TB Seo et al., unpublished data). To examine the hypothesis that one or more molecular component(s) of SMS responsible for growth-promoting activity in the injured peripheral nerve might have a supportive role for improved regenerative responses in CNS axons, we generated a contused rat model and determined the effects of SMS on the regrowth of spinal cord axons. We have found that SMS induced changes in neural tissue responses that may have a positive effect on axonal growth, as demonstrated by enhanced axonal elongation of the corticospinal tract (CST) after SCI. Our data further show that SMS induces $\mathrm{Cdc} 2$ and phosphoErk1/2 protein production in spinal cord axons after injury.

\section{Materials and Methods}

\section{Experimental animals and surgery}

Sprague-Dawley rats (male, 200-250 g; Samtago, Seoul, Korea) were maintained in an animal room with regulated temperature $\left(22^{\circ} \mathrm{C}\right), 60 \%$ humidity, and a $12-\mathrm{h}$ light/dark cycle (lights on 0700 to $1900 \mathrm{~h}$ ). They were allowed to eat commercial pellet chow (Samyang Co., Seoul, Korea) and drink water ad libitum. Rats were anesthetized by injecting intraperitoneally a single dose of a mixture of ketamine $(80 \mathrm{mg} / \mathrm{kg})$ and xylazine $(5 \mathrm{mg} / \mathrm{kg})$. Using aseptic technique, a laminectomy was performed to expose the dura mater of the spinal cord at thoracic levels $9-10$. A contusion injury was given to the exposed dura using the NYU compactor by dropping a 10-g impactor (a cylindrical metal rod tapered to a tip diameter of $2 \mathrm{~mm}$ ) from $2.5-\mathrm{cm}$ height (18). After the suture of the wound in anatomical layers, rats were maintained in standard plastic cages until further treatment. Rat care and all experimental procedures were in accordance with the Animal-use Statement and Ethics Committee approval statement for animal experiments at Daejeon University. A total of 36 rats ( $3-4$ animals per group) were used in this study.

\section{SMS preparation and administration}

Dried SMS, which consists of three herbal components, Panax Ginseng (specimen numbers: 06100501, production area: Geumsan, Chungnam Province, Korea), Ophiopogon Japonicus (specimen numbers: 06190101, production area: Miryang, Gyeongnam Province, Korea), and Schisandra Chinensis (specimen numbers: 06020301, production area: Muju, Jeonbuk Province, Korea) (1:2:1 in dry weight) were obtained from Daejeon University Oriental Medicinal Hospital (Daejeon, Korea; purchased from Hyehwa Herbs. Co.). Dried SMS was recorded and stored for 10 years at the Daejeon University Oriental Medicinal Hospital. Twentythree grams of dried SMS were suspended in 1 liter of distilled water for $2 \mathrm{~h}$, boiled for $3 \mathrm{~h}$, and filtered with Whatman filter paper (Grade 1; Whatman Inc., Clifton, NJ, USA) three times. The extract was frozen at $-70^{\circ} \mathrm{C}$ for $4 \mathrm{~h}$ and then freeze-dried for $24 \mathrm{~h}$. The yield of SMS was $2 \mathrm{~g}$ for $23 \mathrm{~g}$ of the initial raw materials. Purified material was stored at $-20^{\circ} \mathrm{C}$ and used for the experiments after dissolving it in physiological saline solution ( $1 \mathrm{mg}$ of extract residue $/ \mathrm{ml}$ in $0.9 \% \mathrm{NaCl}$ solution). For efficient drug delivery into the nervous system, $10 \mu \mathrm{l}$ of SMS solution or an equal volume of saline was applied into the area of SCI for a 1-min period followed by intraperitoneal supplementation of $0.1 \mathrm{ml}$ solution every other day until the animal's sacrifice.

\section{HPLC analysis}

HPLC analysis of SMS was performed by the previously reported procedures (9). Briefly, SMS solution was centrifuged at $12,000 \mathrm{rpm}$ for $10 \mathrm{~min}$, and standard solutions of Schisandrin (Chromadex, Irvine, CA, USA) and Gomisin A (Chromadex) were diluted to a concentration range of $0-50 \mu \mathrm{g} / \mathrm{ml}$ for standard curves. The supernatant of SMS and standard solutions were analyzed by LC-10AD HPLC system (Shimadzu, Kyoto). The analysis system includes a Thermo Hypersil reverse phase C18 column $(250 \times 4.6 \mathrm{~mm})$ with linear gradient elution at 5-40 min with $\mathrm{CH}_{3} \mathrm{CN}$ and aqueous solution at a flow rate at $1 \mathrm{ml} / \mathrm{min}$. Aliquots $(20 \mu \mathrm{l}$ each) of SMS and standard solutions were injected to the column. Temperature of the column oven was set to $30^{\circ} \mathrm{C}$ and UV detection was at $214 \mathrm{~nm}$. 


\section{Primary cell culture}

For DRG sensory neuron culture, DRG at lumber $4-5$ of the intact rat was dissociated by treatment with $125 \mathrm{U} / \mathrm{ml}$ type XI collagenase (Sigma, St. Louis, MO, USA) in DMEM for $80 \mathrm{~min}$ at $37^{\circ} \mathrm{C}$ and then washed twice with DMEM. Cells were treated with $0.5 \mathrm{mg} / \mathrm{ml}$ type SII trypsin for $15 \mathrm{~min}$, followed by an inhibition reaction for $5 \mathrm{~min}$ in $1 \mathrm{mM}$ EDTA, $100 \mu \mathrm{g} / \mathrm{ml}$ of soybean trypsin inhibitor, and $40 \mu \mathrm{g} / \mathrm{ml}$ of DNase I. Cells $\left(1 \times 10^{5}\right.$ cells $)$ were plated onto $12-\mathrm{mm}$ coverslips (Bellco Glass Inc., Vineland, NJ, USA) precoated with $0.01 \%$ poly-L-ornithine (Sigma) and laminin (0.02 $\mathrm{mg} / \mathrm{ml}$; Collaborative Research, Bedford, MA, USA) and $12 \mathrm{~h}$ later, changed to DMEM containing 5\% fetal bovine serum (GIBCO, Melbourne, Australia) plus 5\% horse serum, $2 \mathrm{mM}$ glutamine, and $1 \%$ penicillinstreptomycin. Cells were treated with $0.5-2.0 \mu \mathrm{g} / \mathrm{ml}$ of SMS, $1-50 \mu \mathrm{g} / \mathrm{ml}$ of $\alpha$-tocopherol (Sigma), or ethanol vehicle $(0.02 \%)$ and then incubated for $48 \mathrm{~h}$ before harvesting them for immunofluorescence staining with anti-neurofilament-200 antibody (NF-200, mouse monoclonal, 1:200; Sigma).

For spinal cord non-neuronal cell culture, a dorsal half of spinal cord covering 1-cm length of the rostral and caudal region from the injury site was dissected from a rat that had been given SCI for 3 days. For DRG sensory neuron culture, DRG at lumbar $4-5$ were prepared from rats that had undergone sciatic nerve injury for 3 days. The procedures of primary DRG neurons and spinal cord non-neuronal cells are essentially the same as described previously (13). Spinal cord non-neuronal cells $\left(1 \times 10^{5}\right.$ cells per 12-mm coverslip) were incubated for $24 \mathrm{~h}$ before the addition of freshly prepared DRG sensory neurons $\left(1 \times 10^{5}\right.$ cells per $12 \mathrm{~mm}$ coverslip). Cocultured cells were treated for $48 \mathrm{~h}$ with $1 \mu \mathrm{g} / \mathrm{ml}$ of SMS, a mixture of $5 \mathrm{nM}$ minocycline plus $0.5 \mu \mathrm{M}$ rolipram, or the equivalent volume of saline and used for immunofluorescence staining with anti-NF-200 antibody (mouse monoclonal, Sigma) and anti-glial fibrillary acidic protein (GFAP) antibody (rabbit polyclonal; Chemicon, Temecula, CA, USA).

Digital images of neuronal process were captured and transferred to the Adobe Photoshop program (version 5.5; Adobe). The number and length of neurite processes exhibiting clear outgrowth (longer than cell body size) from the cell body were analyzed by the iSolution software program (Image and Microscope Technology, Goleta, CA, USA). Mean neurite length was determined by analyzing at least 30 sensory neurons grown on the coverslip.

\section{Immunohistochemistry}

Dissected spinal cord tissues were frozen immediately at $-80^{\circ} \mathrm{C}$ and embedded into the OCT medium. The sections $(20 \mu \mathrm{m})$ were cut using a cryostat and mounted on positively charged slides (Fisher, Pittsburgh, PA, USA). Pretreatment, primary and secondary antibody reactions, and microscopic analysis of sections were performed as described previously (13). The primary antibodies used in the present study were anti-GFAP antibody (rabbit polyclonal, Chemicon), anti-CSPG antibody (mouse monoclonal, CS56; Sigma), anti-NF200 antibody (mouse monoclonal, 1:200; Sigma), and anti-CD11 $\beta$ antibody (mouse monoclonal; BD Bioscience, San Jose, CA, USA); and the secondary antibody was fluorescein-goat anti-mouse (Molecular Probes, Eugene, OR, USA) or rhodamine-goat antirabbit secondary antibodies (Molecular Probes). Cellular nuclei were stained with $2.5 \mu \mathrm{g} / \mathrm{ml}$ of Hoechst 33258 dye (bis-benzimide, Sigma) for $10 \mathrm{~min}$ before the final washing with $0.1 \%$ Triton X-100 in PBS, and the sections were coverslipped with gelatin mount medium. Samples were viewed with a fluorescence microscope (Nikon Eclipse E-600; Nikon, Tokyo) equipped with a digital camera, and the captured images in the computer were analyzed by Adobe Photoshop (Version 5.5). Average number of CD11 $\beta$-stained cells or Hoechststained nuclei in individual images (area: $650 \times 500$ $\mu \mathrm{m}^{2}$ ) were counted from 4 nonconsecutive spinal cord sections per animal.

\section{Western blot analysis}

The dorsal half of the spinal cord tissue covering approximately $1 \mathrm{~cm}$ of rostral and caudal spinal cord at the injury area and the motor cortex area covering $1-4$ $\mathrm{mm}$ posterior to the bregma, $1-4 \mathrm{~mm}$ from the midline with a depth to $1.8 \mathrm{~mm}$ were dissected. The tissues were washed with ice-cold PBS and sonicated under $400-$ $600 \mu \mathrm{l}$ of Triton lysis buffer $(20 \mathrm{mM}$ Tris, $\mathrm{pH} 7.4$, $137 \mathrm{mM} \mathrm{NaCl}, 25 \mathrm{mM} \beta$-glycerophosphate, $\mathrm{pH} 7.14$, $2 \mathrm{mM}$ sodium pyrophosphate, $2 \mathrm{mM}$ EDTA, $1 \mathrm{mM}$ $\mathrm{Na}_{3} \mathrm{VO}_{4}, 1 \%$ Triton $\mathrm{X}-100,10 \%$ glycerol, $5 \mu \mathrm{g} / \mathrm{ml}$ leupeptin, $5 \mu \mathrm{g} / \mathrm{ml}$ aprotinin, $3 \mu \mathrm{M}$ benzamidine, $0.5 \mathrm{mM}$ DTT, and $1 \mathrm{mM} \mathrm{PMSF}$ ); and $25 \mu \mathrm{g}$ protein of each sample was used for western analysis. Quantitative analysis of protein bands in the autoradiographic images was determined using the i-Solution software. The antibodies used in the present study were anti-Cdc2 antibody (mouse monoclonal, Santa Cruz Biotech), antiErk1/2 antibody (rabbit polyclonal, Cell Signaling), anti-phospho-Erk1/2 antibody (rabbit polyclonal, Cell Signaling), and anti-actin antibody (rabbit polyclonal; ICN Biomedicals, Cleveland, OH, USA) as primary antibodies, and horseradish peroxidase (HRP)-conjugated secondary antibodies (goat anti-rabbit, from Santa Cruz Biotech or sheep anti-mouse, from Amersham 
Biosciences, Piscataway, NJ, USA).

\section{Anterograde tracing}

Fluorescent lipophilic carbocyanine dye 1,1'-dioctodecyl-3,3,3',3'tetramethylindocarbocyanine perchlorate (DiI) (Molecular Probes), an anterograde tracer, was injected into the motor cortical area at the time when the SCI was given. The rats were anesthetized with a mixture of ketamine $(80 \mathrm{mg} / \mathrm{kg})$ and xylazine $(5 \mathrm{mg} / \mathrm{kg})$ and placed in a stereotaxic instrument (Harvard Apparatus, Holliston, MA, USA). The rat's head skin was incised, a hole was drilled in the skull, a glass capillary filled with DiI ( $5 \mu \mathrm{l}$ of $3 \%$ in DMSO) was inserted, and DI was injected at a flow rate of $1.6 \mu \mathrm{l} / \mathrm{min}$ for $3 \mathrm{~min}$ into the motor cortex $(2.0-\mathrm{mm}$ posterior to the Bregma, 2.3-mm lateral to the mid-line, $1.5-\mathrm{mm}$ ventral to the dura surface) on the left side of the brain by using a picoinjector (Harvard Apparatus PLI-100). DiI-labeled CST axons of the spinal cord sections $(20 \mu \mathrm{m})$ were analyzed 2 weeks later under Nikon fluorescence microscope (Eclipse E-600).

\section{Statistical analysis}

Data were presented as the mean \pm S.E.M. The mean values in individual groups were compared by one-way ANOVA with Tukey's post hoc test (SPSS version 14.0; SPSS Korea, Data Solution Inc., Seoul, Korea), and statistically significant difference was reported as $P<0.05$.

\section{Results}

To validate the chemical profile of SMS extract, we performed HPLC analysis for two of ingredients in SMS, Schisandrin and Gomisin-A. The HPLC chromatogram of SMS solution showed the peaks of Schisandrin and Gomisin-A at 33.0 and $34.1 \mathrm{~min}$, respectively, which coincided with those of the standard solutions (Fig. 1A). The peak profile featuring higher amplitude in Schisandrin relative to Gomisin-A was similarly observed in the previous study (14). We evaluated the potential of SMS to increase neurite outgrowth of DRG sensory neurons using $\alpha$-tocopherol as a positive control. Cultured DRG neurons revealed the highest neurite outgrowth with treatments of SMS at $1.0 \mu \mathrm{g} / \mathrm{ml}$ and of $\alpha$-tocopherol at $10 \mu \mathrm{g} / \mathrm{ml}$ (Fig. 1: B and C). Comparison

A

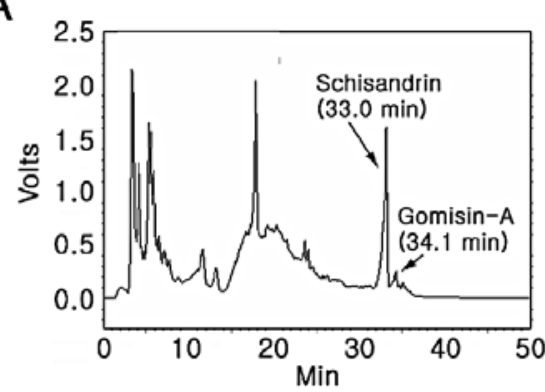

B
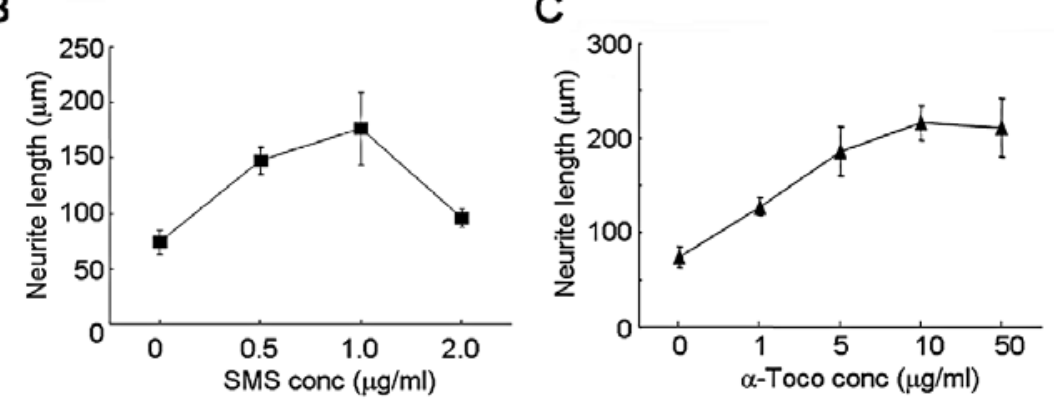

D

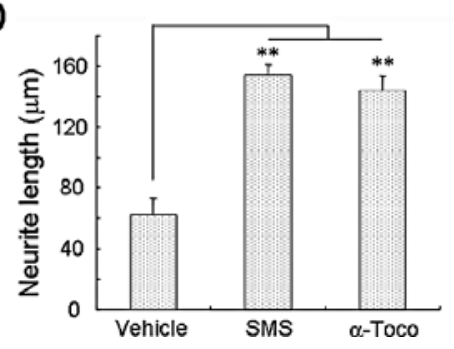

E

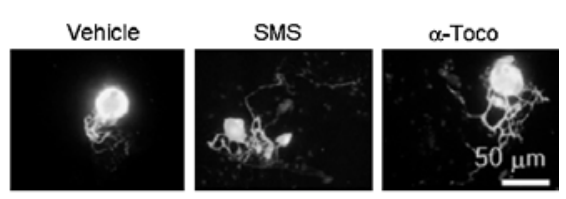

Fig. 1. SMS facilitates neurite outgrowth of DRG sensory neurons. A: HPLC profile of SMS extract. Two peaks of the SMS solution at $33.0 \mathrm{~min}$ and $34.1 \mathrm{~min}$ coincide with those of Schisandrin and Gomisin-A standard solutions, respectively. B and C: Dose-dependent responses in the neurite outgrowth of DRG sensory neurons. Cells were cultured for 2 days at different concentrations of SMS and $\alpha$-tocopherol as indicated in the figure. Mean \pm S.E.M. $(\mathrm{N}=4)$. $\mathrm{D}$ and $\mathrm{E}$ : Comparison of mean neurite length among cultured cells treated with SMS $(1 \mu \mathrm{g} / \mathrm{ml}), \alpha$-tocopherol $(\alpha$-Toco, $10 \mu \mathrm{M})$, and $0.02 \%$ of ethanol solution as a vehicle. Mean neurite length in SMS- or $\alpha$ tocopherol-treated cells was significantly longer than the vehicle control $(* * P<0.01, \mathrm{~N}=4$, oneway ANOVA). No significant difference in mean neurite length was found between SMS- and $\alpha$ tocopherol-treated groups. Representative fluorescence images of NF-200-stained neurons are shown in photo $\mathrm{E}$. 
A

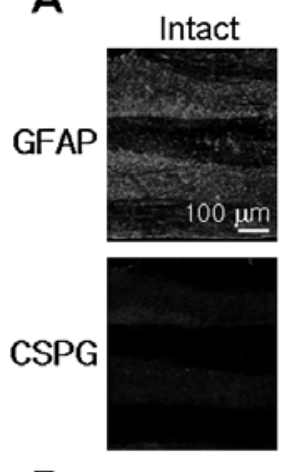

B

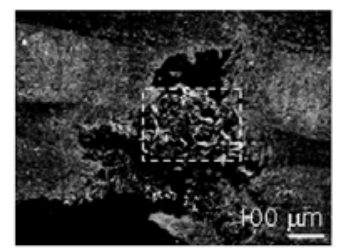

Saline
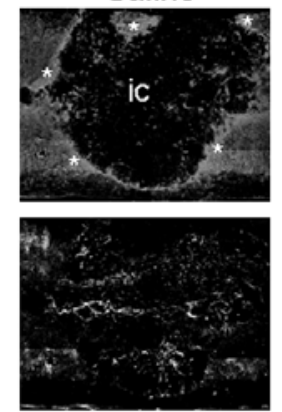

C

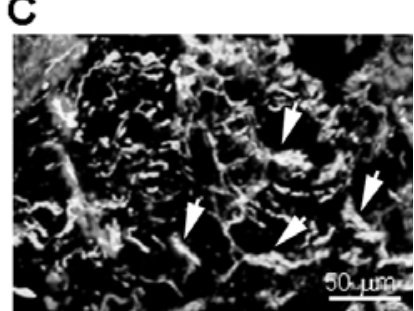

Fig. 2. SMS affects the formation of injury cavity in the rat spinal cord. Two weeks after contusion injury at T9-10 levels followed by saline or SMS administration, horizontal sections were prepared and used for immunofluorescence staining for the detection of GFAPlabeled astrocytes and glial scar protein CSPG. Immunohistochemistry experiments for spinal cord sections from intact animals were essentially the same. A: The injury cavity area (ic) surrounded by GFAPlabeled reactive astrocytes (marked by asterisks) was smaller in the SMS-treated group than the saline control. Images in upper and lower panels show GFAP-stained astrocytes and CSPG-stained meshwork in the same set of sections, respectively. B: Merged image of GFAPand CSPG-stained section prepared from injured spinal cord with SMS treatment. C: An enlarged view of the rectangular area in photo B. Trabecular meshwork, which was identified by CSPG-labeled extensions, was clearly observed within the injury cavity (arrows).

of mean neurite length showed significant increase in cells treated with $1.0 \mu \mathrm{g} / \mathrm{ml} \mathrm{SMS} \mathrm{or} 10 \mu \mathrm{g} / \mathrm{ml} \alpha$ tocopherol compared to the vehicle control (Fig. 1: D and $\mathrm{E})$.

To examine the effects of SMS extract on injury cavity formation after SCI, we determined in vivo distribution of reactive astrocytes and CSPG in the spinal cord tissue. GFAP-labeled astrocytes were clearly observed with demarcating cell layers around the lesion cavity (Fig. 2A). The lesion cavity in SMS-treated tissue was confined to a more limited area compared to the saline control, and the trabecular meshwork within in the cavity, which was identified by CSPG immunostaining, was seen more clearly in the SMS-treated group (Fig. 2A). Signals of CSPG, one of the major glial scar ingredients, were detected in the injury cavity of salineand SMS-treated animals, but not in the intact control. Merged image analysis showed that a majority of CSPG signals were localized within the injury cavity (Fig. 2: B

A
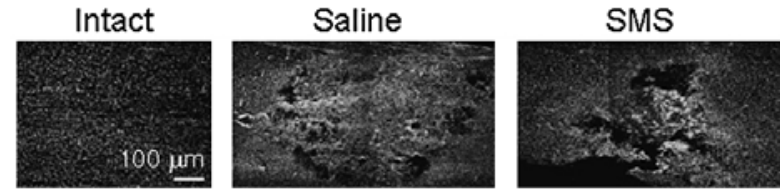

B
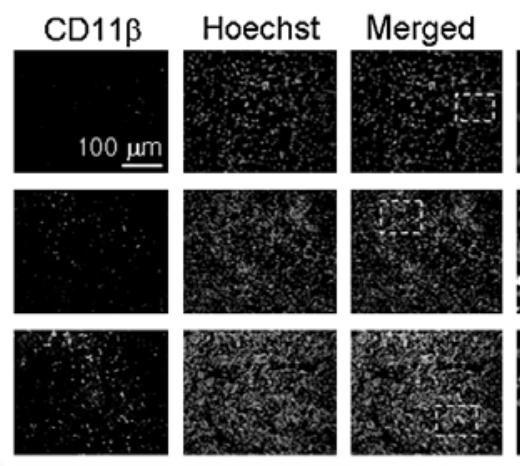

Enlarged
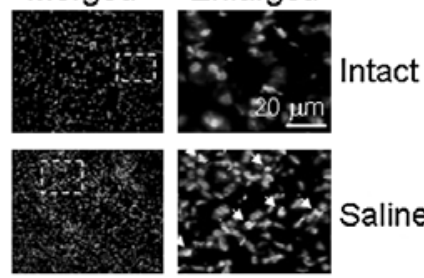

Saline
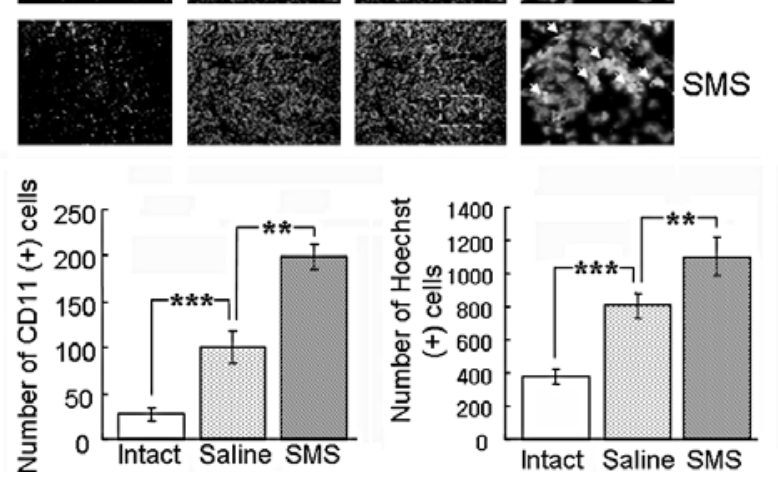

Fig. 3. SMS treatment increases non-neuronal cell population within the injury cavity. Horizontal spinal cord sections were analyzed 2 weeks after contusion injury. A: Hoechst nuclear staining of individual cells in the spinal cord tissue. B: Hoechst nuclear staining and immunofluorescence staining of CD1 $1 \beta$ protein around the injury cavity. Rectangular areas in the merged images for individual groups were enlarged, and CD11 $\beta$-positive cells were indicated by arrows. The graphs in photo $\mathrm{B}$ show the number of CD11 $\beta$ - and Hoechst 33258-positive cells in the image fields (mean \pm S.E.M., Number of animals $=4, * * P<0.01, * * * P<0.001$, one-way ANOVA).

and C). Immunohistochemical analysis further showed that the number of cells positive for $\mathrm{CD} 11 \beta$ protein and Hoechst nuclear staining in the close vicinity of the lesion cavity were significantly higher in saline- or SMS-treated groups compared to the untreated control (Fig. 3: A and B). SMS treatment increased significantly the number of cells positive for CD11 $\beta$ protein- or Hoechst staining above the saline controls. Merged image analysis showed complete overlapping of all the signals of CD11 $\beta$-positive cells with those of Hoechststained nuclei, but many of Hoechst-stained nuclei were devoid of CD1 $1 \beta$ signals.

To examine axonal outgrowth into the lesion cavity, elongated axons into the cavity zone was identified by immunofluorescence staining of neuron-selective NF200 protein. In the saline-treated group, NF-200 signals were observed as scattered and fragmented entities, whereas most of the NF-200-positive signals were seen as elongated fibers with intense staining (Fig. 4). We 

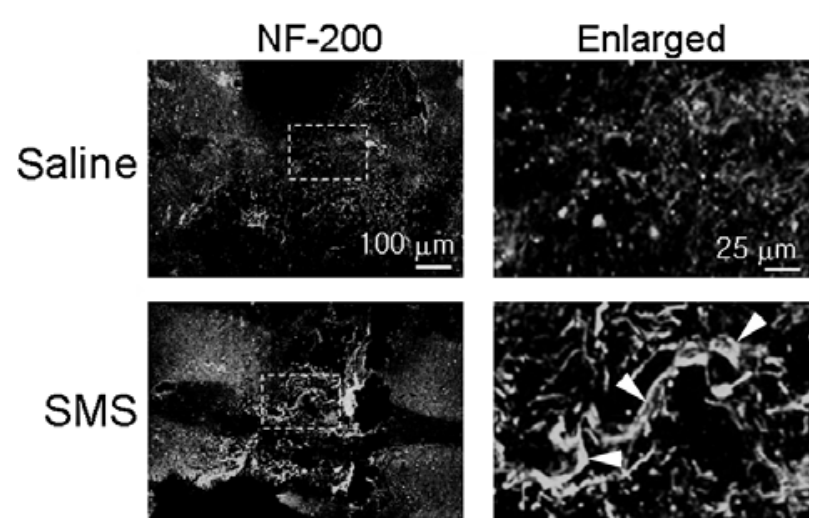

Fig. 4. SMS treatment increases axonal staining within the injury cavity. Two weeks after contusion injury at T9-T10 levels, horizontal sections were used for immunofluorescence staining for the detection of NF-200-labeled axons. Enlarged images for the rectangular area within the injury cavity illustrate more axonal processes in SMStreated group compared with the saline control (arrowheads).

further investigated the regrowth of CST axons around the lesion cavity by tracing DiI-labeled axons. While DiI-labeled CST axons were clearly observed within the dorsomedial white matter area, collateral arborization extending into the gray matter zone was observed as descending axons became closer to the injury site (Fig. 5A). Although the extension of the DiI-labeled CST axon bundle was disrupted mostly at the injury boundary, axonal elongation was observed as a detour path around the injury cavity (Fig. 5B). This process was much more intense in the SMS-treated group, and particularly stronger labeling was noted at the border of the injury cavity. DiI-labeling of CST axons at the caudal spinal cord was much lower in both saline-treated and SMS-treated groups compared to the rostral spinal cord sections prepared from the corresponding animals. Yet, overall staining intensity was stronger in the SMStreated group than in the saline-treated group (Fig. 5C).

Enhanced neurite outgrowth of DRG sensory neurons in culture can be potentiated by nerve injury pretreatment (19). Here, we investigated the effects of SMS treatment on neurite outgrowth of DRG neurons that were co-cultured with non-neuronal cells prepared from injured spinal cord in adult rats. As shown in Fig. 6 (A and B), SMS treatment improved neurite outgrowth in cultured cells. Addition of a mixture of the antibiotic minocycline and the selective cAMP phosphodiesterase (PDE) inhibitor rolipram, known to facilitate regrowth of injured CNS axons $(20,21)$, similarly improved neurite outgrowth. It was noted that the number of non-neuronal cells and their clustered populations, as identified by Hoechst nuclear staining, were elevated by SMS treatment compared to the saline control (Fig. 6A). Furthermore, a dense population of GFAP-stained

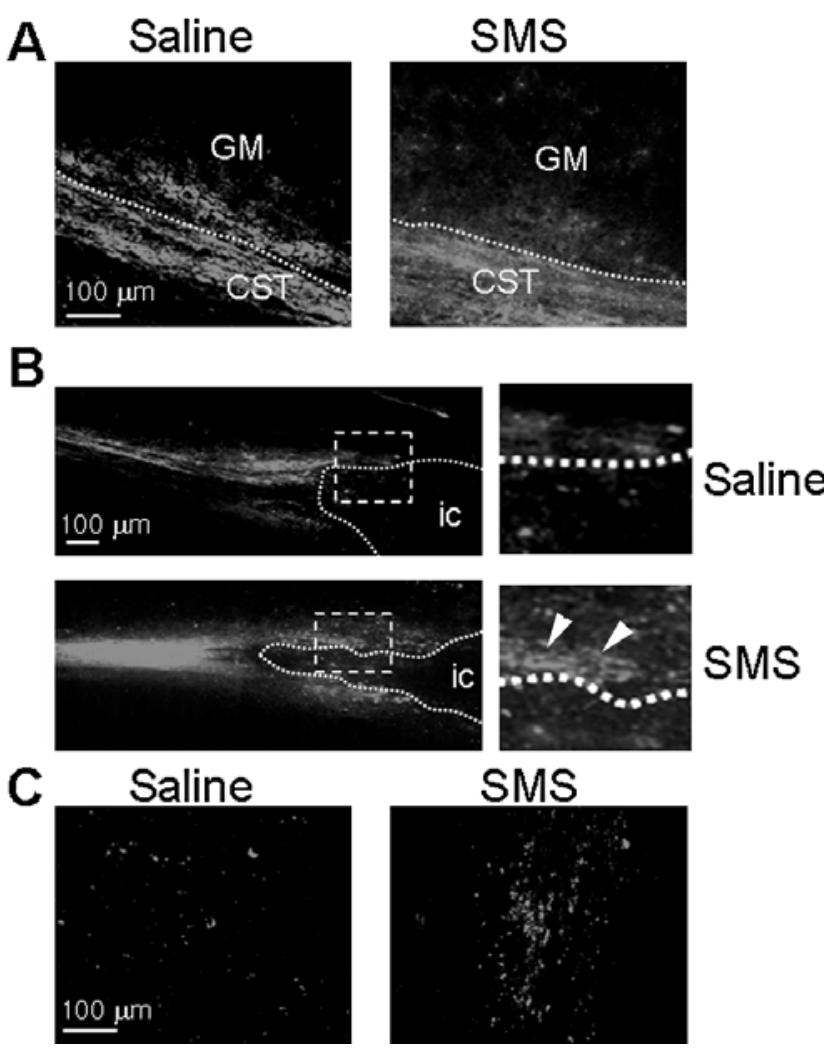

Fig. 5. SMS treatment improves the regrowth of CST axons in the injured spinal cord. At the time of SCI, DiI was microinjected into the motor cortical area in the brain, and DiI-labeled CST axons in the injured spinal cord were analyzed 2 weeks later from the horizontal sections. A: Fluorescence images of DiI-labeled sections at 5-mm distance rostral to the lesion cavity. The boundary between gray matter (GM) and CST was marked with a dotted line. B: CST axons at the injury cavity (ic) zone. More intense Dil staining of CST axons was seen in the vicinity of the injury cavity. Enlarged images near the boundary of the injury cavity show stronger DiI staining in the SMS group than the saline control (arrowheads). The dotted lines indicate the boundary of the injury cavity. C: DiI-labeled images at caudal cord sections at a distance less than $5 \mathrm{~mm}$ from the injury cavity.

astrocytes and Hoechst-stained nuclei was seen around the soma and neurites of DRG neurons (Fig. 6C).

We have recently found that Erk1/2 and Cdc2 pathways are activated during axonal regeneration in peripheral sciatic nerves $(9,13)$. Here, regulation of phospho-Erk1/2 and Cdc 2 proteins by SMS treatment was investigated in the dorsal spinal cord and in the motor cortex where the cell bodies of CST axons are located. Phospho-Erk1/2 was barely detected in the intact spinal cord and motor cortical tissues, but greatly increased 1 week after injury. SMS treatment significantly elevated phospho-Erk $1 / 2$ protein levels in the motor cortex but not in the injury area (Fig. 7A). Similarly, Cdc2 protein was induced in the spinal cord after injury, and further increased by SMS treatment (Fig. 7B). However, Cdc2 protein in the motor cortical 


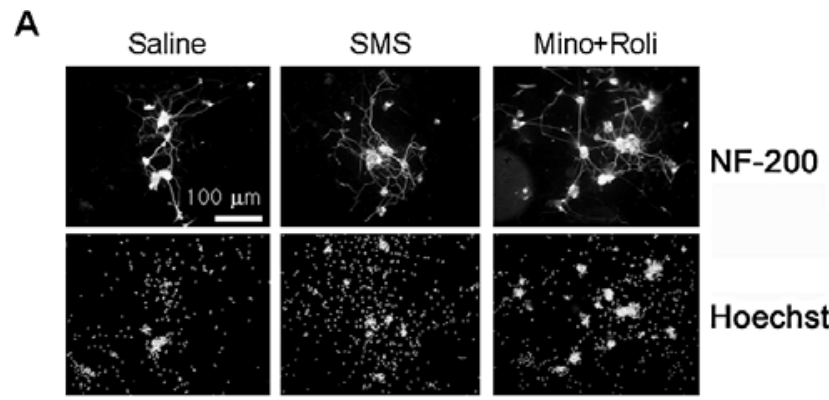

B

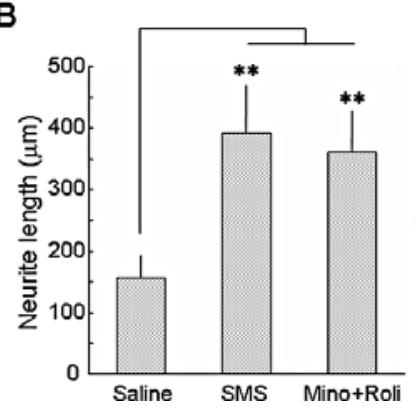

Fig. 6. Enhanced neurite outgrowth by SMS treatment in cocultured DRG sensory neurons. DRG sensory neurons were co-cultured with glial cells prepared from the injured spinal cord, and treated with saline, SMS $(1 \mu \mathrm{g} / \mathrm{ml})$, or minocycline $(5 \mathrm{nM})$ and rolipram $(0.5 \mu \mathrm{M})$. Cells were harvested $48 \mathrm{~h}$ later for immunofluorescence staining with NF-200 and GFAP for the detection of DRG sensory neurons and astrocytes together with Hoechst nuclear counterstaining. A: Representative images of cell staining. The images in the upper and lower panels showed NF-200-stained neurons and Hoechst stained nuclei of all individual cells in the same set of sections, respectively. B: Quantitation of neurite length of DRG sensory neurons. Neurite length of DRG sensory neurons cocultured with spinal cord glial cells was significantly increased by SMS or by minocycline plus rolipram (Mino + Roli) treatment compared to the saline control $(* * P<0.01, \mathrm{~N}=4$, one-way ANOVA). C: Double immunofluorescence image of NF-200-labeled neuron (arrowheads) with GFAP-positive cells (smaller arrows). Note the dense population of astrocytes and Hoechst-stained nuclei around the long neurite (arrowheads).

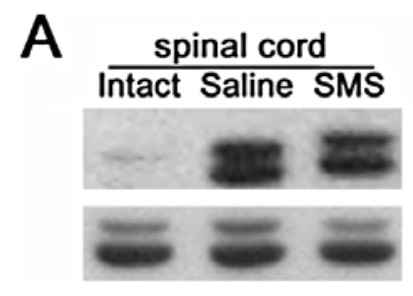

B

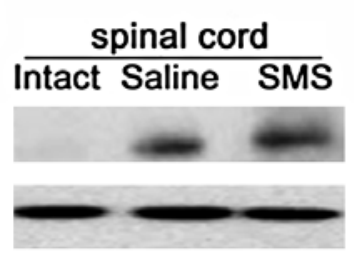

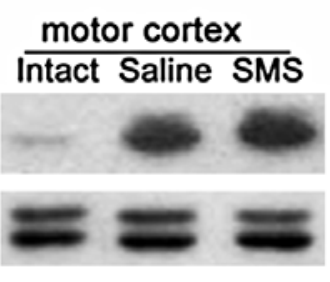
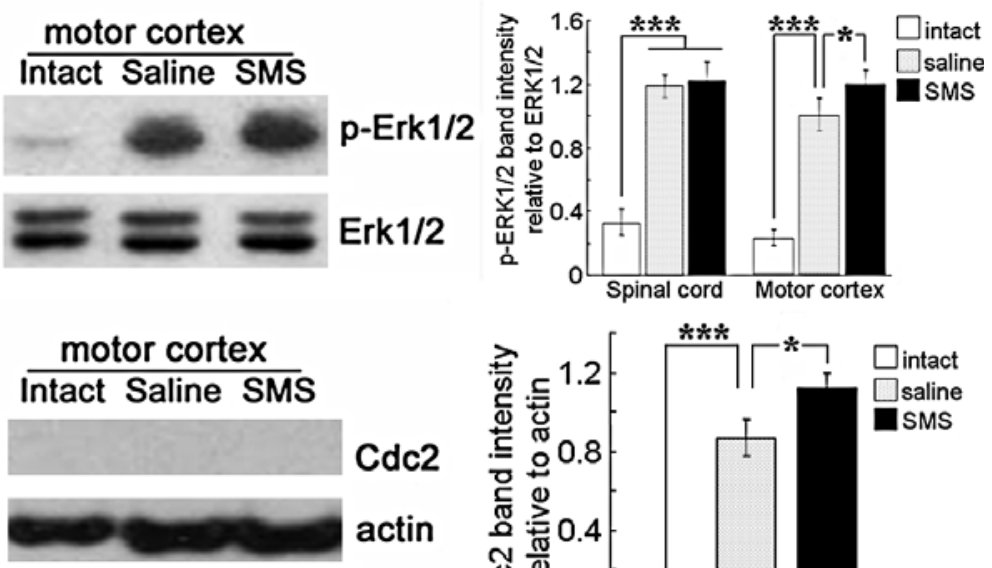

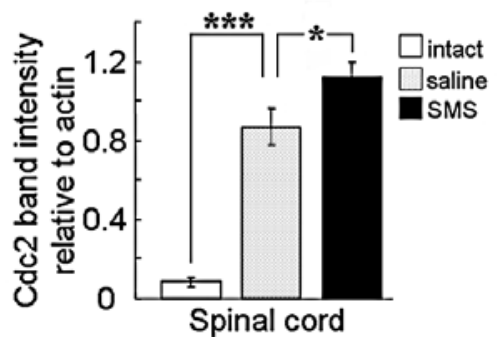

Fig. 7. Regulation of phospho-Erk $1 / 2$ and Cdc2 protein levels by SMS treatment at the injury area of the spinal cord and at the motor cortex. Western blot analysis of phospho-Erk1/2 (p-Erk1/2) (A) and Cdc2 proteins (B). In panels A and B, the same blots were used to determine total Erk1/2 and actin protein levels as internal loading controls, respectively. Quantitation of band intensities of phospho-Erk1/2 and Cdc2 relative to total Erk1/2 and actin proteins is shown in the graphs (mean \pm S.E.M., $\mathrm{N}=3, * P<0.05, * * * P<0.001$, one-way ANOVA). The $\mathrm{X}$-ray film images in panels A and $\mathrm{B}$ are representative ones from three independent experiments.

area showed no expression by any treatments (Fig. 7B).

\section{Discussion}

Growing evidence shows that herbal drugs can function to repair damaged neurons. Extracts of Hominis placenta and ginsenosides have been shown to promote peripheral axonal regeneration $(22,23)$, and neuroprotective effects of herbal drugs such as ginkgo biloba, danshen, and ginseng components in the injured spinal cord tissues or ischemic brain were reported $(24-26)$. According to the theory of traditional Chinese medicine, SMS is believed to be effective for invigorating the vital energy and producing and converging the vital essence, which is critical for physiological regulation of the circulatory system. Recent studies have provided evidence that the protective effect of SMS is mediated by regulating the damage caused by free radicals such as 
reactive oxygen species or nitric oxide in diverse tissues and organs including the nervous system $(14,27,28)$.

As an initial step to explore the potential growthpromoting activity of SMS on injured axons, neurite outgrowth of DRG sensory neurons was investigated in the presence of SMS and with $\alpha$-tocopherol treatment as a positive control. $\alpha$-Tocopherol is a well-known antioxidant and has been examined for the treatment of diverse cardiovascular and neurological disorders such as stroke, Alzheimer's disease, amyotrophic lateral sclerosis, and SCI (29-32). At the molecular level, $\alpha$-tocopherol appears to attenuate LPS-induced production of inflammatory cytokines and NF- $\kappa \mathrm{B}$ and decrease TNF- $\alpha$ expression in activated macrophages $(33,34)$. It was shown that $\alpha$-tocopherol treatment improved neurite outgrowth of cultured retinal ganglion cells (35). Having noted that the protective effects of SMS on oxidative damages in different kind of cells or tissues might be shared mechanistically with those of $\alpha$ tocopherol, several studies reported similar protection by $\alpha$-tocopherol $(14,16,36,37)$. Our data showed that neurite outgrowth of DRG sensory neurons was enhanced to a similar level by treatment of either SMS or $\alpha$-tocopherol in comparison to the untreated control, which implicates physiological significance of the antioxidant activity of SMS for axonal regeneration.

Since we found growth-promoting activity of injured sciatic nerve by SMS treatment (TB Seo et al., unpublished data), we examined whether SMS has a similar effect on the induction of axonal regenerative responses after SCI. The lesion cavity, formed 2 weeks after SCI in the dorsal spinal cord and surrounded by a layer of demarcated reactive astrocytes, was confined to a smaller area in the SMS-treated group than the saline control. CSPG staining within the injury cavity was clearly observed in both saline- and SMS-treated groups. CSPG, a major constituent of glial scar acting as an inhibitory barrier against axonal regrowth, is highly expressed in reactive astrocytes and secreted into the extracellular matrix (1). Thus, its presence in the inside of the injury cavity as well as surrounding glial scar may negatively affect axonal growth in both the saline- and SMS-treated group. Yet, the filamentous pattern of astrocytic extensions, as observed in SMS-treated tissue, may form a trabecular meshwork within the cavity (Fig. 1C), which may function as a bridge for axonal outgrowth through the cavity $(38,39)$. The slightly enhanced elongation of CST axons in the SMS group could be attributed partly to the trabecular formation (see Fig. 4).

Considering that SMS is a mixture of numerous components extracted from three different galenicals, its effect on regenerative axons is presumably the consequence of diverse interactions at the injured tissue (i.e., direction actions on axons vs. surrounding nonneuronal cells and other components). Direct activity of SMS on injured spinal cord axons was investigated by histochemical analysis. Immunofluorescence staining of neuronal protein NF-200 revealed intense, elongated axons within the lesion cavity in SMS-treated animals, whereas fragmentary and scattered staining was seen in the saline control. Anterograde tracing of DiI-labeled CST axons further supports enhanced axonal regrowth by SMS treatment. We found intense collateral sprouting of rostral CST axons into the gray matter in both SMS- and saline-treated groups. CST axonal arborization developed more intensely within and around the injury boundary by SMS treatment. Furthermore, SMS treatment increased the signals of DiI-labeled CST axons at the caudal spinal cord. These axons might originate from the detour path surrounding the injury cavity or the direct trabecular connection through the lesion cavity. Whether the observed CST axons at the caudal zone were the consequence of bona fide axonal regeneration or from collateral sprouting of the spared axons remains to be determined. Measurement of retrogradely-labeled cortical neurons in the motor cortical area after DiI injection at the location caudal to the injury site may provide one approach to determine the levels of regenerating axons. Although increases in staining intensity of DiI-labeled axons in the SMStreated group were subtle compared to the saline control, the accompanying physiological consequence via the correct synaptic targeting to the motor neurons in the central pattern generator (CPG) and in turn, functional recovery of motor activity might be of significance, considering the previous notion that $1 \%-2 \%$ axonal regeneration could induce functional improvement (40, 41).

To examine the effects of SMS on non-neuronal cells in the injured spinal cord, we prepared a coculture of DRG sensory neurons with glial cells. The extent of neurite outgrowth of DRG sensory neurons was reduced when cocultured with the glial cells prepared from injured spinal cord (unpublished observation). SMS treatment improved neurite outgrowth of DRG neurons in culture, suggesting that SMS might suppress the inhibitory activity mediated by glial cells. Reactive astrocytes are the most abundant among non-neuronal cells in the injured CNS tissue, and thus, inhibitory molecules released from astrocytes such as CSPG could be the potential blocking target of SMS.

We further investigated whether SMS-mediated axonal regeneration is linked to molecular events in the injured neurons. The present data demonstrate robust increases of phospho-Erk $1 / 2$ and $\mathrm{Cdc} 2$ proteins in the 
injury area after SCI. Interestingly, phospho-Erk1/2, but not $\mathrm{Cdc} 2$, was induced in the motor cortical area where the pyramidal neurons for CST axons are located. Noting that SMS treatment did not alter phospho-Erk1/2 protein levels in the injury area, but upregulated phospho-Erk $1 / 2$ in the cortical area, a possible mechanism of SMS regulation of Erk1/2 might involve facilitated retrograde transport of phospho-Erk1/2 into the cell body through the axon trunk and activate transcriptional factors such as CREB, leading to target gene expression $(42-44)$. In contrast, upregulation of Cdc2 protein by SMS was restricted to the local injury area. There is evidence demonstrating that $\mathrm{Cdc} 2$ is expressed in astrocytes after SCI (unpublished data). As has been implicated by Cdc2-mediated migration of Schwann cells and cancer cells $(13,45)$, locally upregulated Cdc2 activity by SMS in non-neuronal cells (e.g., astrocytes) could promote their migration into the injury cavity as observed by the increased number of Hoechststained nuclei by SMS treatment. Cells that migrated into the injury cavity could be involved in trabecula formation and contribute to axonal regeneration.

Although chemical analysis of active ingredients of SMS is the prerequisite for understanding the mechanism underlying the effects of SMS on axonal regeneration at the molecular level, possible functions of SMS in inflammatory and immune responses deserve to be mentioned. The present data demonstrate that $\mathrm{CD} 11 \beta$ labeled cells, which may include macrophages, microglia, and neutrophils, are increased in injured spinal cord by SMS treatment. Since administration or infiltration of monocytes into the matrix area around the injury site can contribute to spinal cord repair $(46,47)$, further characterization of specific cell types and time window of induction would be critical for understanding the role of SMS in inflammatory and immune responses after SCI.

\section{Acknowledgments}

This work was supported by grants from the Korea Research Foundation (C00158 and E00116) to U. Namgung.

\section{References}

1 Yiu G, He Z. Glial inhibition of CNS axon regeneration. Nat Rev Neurosci. 2006;7:617-627.

2 Aigner L, Arber S, Kapfhammer JP, Laux T, Schneider C, Botteri $\mathrm{F}$, et al. Overexpression of the neural growth-associated protein GAP-43 induces nerve sprouting in the adult nervous system of transgenic mice. Cell. 1995;83:269-278.

3 Bomze HM, Bulsara KR, Iskandar BJ, Caroni P, Skene JH. Spinal axon regeneration evoked by replacing two growth cone proteins in adult neurons. Nat Neurosci. 2001;4:38-43.
4 Funakoshi H, Frisén J, Barbany G, Timmusk T, Zachrisson O, Verge VM, et al. Differential expression of mRNAs for neurotrophins and their receptors after axotomy of the sciatic nerve. J Cell Biol. 1993;123:455-465.

5 Johnson EM Jr, Taniuchi M, DiStefano PS. Expression and possible function of nerve growth factor receptors on Schwann cells. Trends Neurosci. 1988;11:299-304.

6 Vavrek R, Girgis J, Tetzlaff W, Hiebert GW, Fouad K. BDNF promotes connections of corticospinal neurons onto spared descending interneurons in spinal cord injured rats. Brain. 2006;129:1534-1545.

7 Pearse DD, Pereira FC, Marcillo AE, Bates ML, Berrocal YA, Filbin MT, et al. cAMP and Schwann cells promote axonal growth and functional recovery after spinal cord injury. Nat Med. 2004;10:610-616.

8 Kobayashi NR, Fan DP, Giehl KM, Bedard AM, Wiegand SJ, Tetzlaff W. BDNF and NT-4/5 prevent atrophy of rat rubrospinal neurons after cervical axotomy, stimulate GAP-43 and Talpha1tubulin mRNA expression, and promote axonal regeneration. J Neurosci. 1997;17:9583-9595.

9 Seo TB, Oh MJ, You BG, Kwon KB, Chang IA, Yoon JH, et al. ERK1/2-mediated Schwann cell proliferation in the regenerating sciatic nerves by treadmill training. J Neurotrauma. In press.

10 Koprivica V, Cho KS, Park JB, Yiu G, Atwal J, Gore B, et al. EGFR activation mediates inhibition of axon regeneration by myelin and chondroitin sulfate proteoglycans. Science. 2005; 310:106-110.

11 Desbarats J, Birge RB, Mimouni-Rongy M, Weinstein DE, Palerme JS, Newell MK. Fas engagement induces neurite growth through ERK activation and p35 upregulation. Nat Cell Biol. 2003;5:118-125.

12 Sheu JY, Kulhanek DJ, Eckenstein FP. Differential patterns of ERK and STAT3 phosphorylation after sciatic nerve transection in the rat. Exp Neurol. 2000;166:392-402.

13 Han IS, Seo TB, Kim KH, Yoon JH, Yoon SJ, Namgung U. Cdc2-mediated Schwann cell migration during peripheral nerve regeneration. J Cell Sci. 2007;120:246-255.

14 Nishida H, Kushida M, Nakajima Y, Ogawa Y, Tatewaki N, Sato S, et al. Amyloid- $\beta$-induced cytotoxicity of PC- 12 cell was attenuated by Shengmai-san through redox regulation and outgrowth induction. J Pharmacol Sci. 2007;104:73-81.

15 Chen J, Wu G, Li S, Yu T, Xie Y, Zhou L, et al. Shengmai (a traditional Chinese herbal medicine) for heart failure. Cochrane Database Syst Rev. 2007;4:CD005052.

16 Wang NL, Chang CK, Liou YL, Lin CL, Lin MT. Shengmai San, a Chinese herbal medicine protects against rat heat stroke by reducing inflammatory cytokines and nitric oxide formation. J Pharmacol Sci. 2005;98:1-7.

17 Gurney ME, Pu H, Chiu AY, Dal Canto MC, Polchow CY, Alexander DD, et al. Motor neuron degeneration in mice that express a human $\mathrm{Cu}, \mathrm{Zn}$ superoxide dismutase mutation. Science. 1994;264:1772-1775.

18 Gruner JA. A monitored contusion model of spinal cord injury in the rat. J Neurotrauma. 1992;9:123-126.

19 Smith, DS, Skene JH. A transcription-dependent switch controls competence of adult neurons for distinct modes of axon growth J Neurosci. 1997;17:646-658.

20 Stirling DP, Khodarahmi K, Liu J, McPhail LT, McBride CB, Steeves JD, et al. Minocycline treatment reduces delayed oligodendrocyte death, attenuates axonal dieback, and improves 
functional outcome after spinal cord injury. J Neurosci. 2004;24: 2182-2190.

21 Nikulina E, Tidwell JL, Dai HN, Bregman BS, Filbin MT. The phosphodiesterase inhibitor rolipram delivered after a spinal cord lesion promotes axonal regeneration and functional recovery. Proc Natl Acad Sci U S A. 2004;101:8786-8790.

22 Seo TB, Han IS, Yoon JH, Seol IC, Kim YS, Jo HK, et al. Growth-promoting activity of Hominis Placenta extract on regenerating sciatic nerve. Acta Pharmacol Sin. 2006;27:50-58.

23 Tsai CC, Lu MC, Chen YS, Wu CH, Lin CC. Locally administered nerve growth factor suppresses ginsenoside $\mathrm{Rb} 1$ enhanced peripheral nerve regeneration. Am J Chin Med. 2003;31:665-673.

24 Ao Q, Sun XH, Wang AJ, Fu PF, Gong K, Zuo HC, et al. Protective effects of extract of Ginkgo biloba (EGb 761) on nerve cells after spinal cord injury in rats. Spinal Cord. 2006;44:662-667.

25 Xia WJ, Yang M, Fok TF, Li K, Chan WY, Ng PC, et al. Partial neuroprotective effect of pretreatment with tanshinone IIA on neonatal hypoxia-ischemia brain damage. Pediatr Res. 2005;58: 784-790.

26 Liao B, Newmark H, Zhou R. Neuroprotective effects of ginseng total saponin and ginsenosides $\mathrm{Rb} 1$ and $\mathrm{Rg} 1$ on spinal cord neurons in vitro. Exp Neurol. 2002;173:224-234.

27 Ichikawa H, Konishi T. In vitro antioxidant potentials of traditional Chinese medicine, Shengmai San and their relation to in vivo protective effect on cerebral oxidative damage in rats. Biol Pharm Bull. 2002;25:898-903.

28 Chang CK, Chang CP, Liu SY, Lin MT. Oxidative stress and ischemic injuries in heat stroke. Prog Brain Res. 2007;162:525546.

29 Gaziano JM. Vitamin E and cardiovascular disease: observational studies. Ann N Y Acad Sci. 2004;1031:280-291.

30 Di Matteo V, Esposito E. Biochemical and therapeutic effects of antioxidants in the treatment of Alzheimer's disease, Parkinson's disease, and amyotrophic lateral sclerosis. Curr Drug Targets CNS Neurol Disord. 2003;2:95-107.

31 Cristante AF, Barros Filho TE, Oliveira RP, Marcon RM, Rocha ID, Hanania FR, et al. Antioxidative therapy in contusion spinal cord injury. Spinal Cord. 2009;47:458-463.

32 Ascherio A, Weisskopf MG, O'reilly EJ, Jacobs EJ, McCullough ML, Calle EE, et al. Vitamin E intake and risk of amyotrophic lateral sclerosis. Ann Neurol. 2005;57:104-110.

33 Godbout JP, Berg BM, Krzyszton C, Johnson RW. Alphatocopherol attenuates NFkappaB activation and pro-inflammatory cytokine production in brain and improves recovery from lipopolysaccharide-induced sickness behavior. J Neuroimmunol. 2005;169:97-105.

34 Devaraj S, Jialal I. Alpha-tocopherol decreases tumor necrosis factor-alpha mRNA and protein from activated human monocytes by inhibition of 5-lipoxygenase. Free Radic Biol Med. 2005;38:1212-1220.

35 Lucius R, Sievers J. Postnatal retinal ganglion cells in vitro: protection against reactive oxygen species (ROS)-induced axonal degeneration by cocultured astrocytes. Brain Res. 1996;743:5662 .

36 Wang NL, Liou YL, Lin MT, Lin CL, Chang CK. Chinese herbal medicine, Shengmai San, is effective for improving circulatory shock and oxidative damage in the brain during heatstroke. J Pharmacol Sci. 2005;97:253-265.

37 Nishida H, Ichikawa H, Konishi T. Shengmai-san enhances antioxidant potential in $\mathrm{C} 2 \mathrm{C} 12$ myoblasts through the induction of intracellular glutathione peroxidase. J Pharmacol Sci. 2007; 105:342-352.

38 Schwab ME. Repairing the injured spinal cord. Science. 2002; 295:1029-1031.

39 Hill CE, Beattie MS, Bresnahan JC. Degeneration and sprouting of identified descending supraspinal axons after contusive spinal cord injury in the rat. Exp Neurol. 2001;171:153-169.

40 Li Y, Field PM, Raisman G. Repair of adult rat corticospinal tract by transplants of olfactory ensheathing cells. Science. 1997; 277:2000-2002.

41 Li Y, Field PM, Raisman G. Regeneration of adult rat corticospinal axons induced by transplanted olfactory ensheathing cells. J Neurosci. 1998;18:10514-10524.

42 Hanz S, Fainzilber M. Retrograde signaling in injured nerve the axon reaction revisited. J Neurochem. 2006;99:13-19.

43 Perlson E, Hanz S, Ben-Yaakov K, Segal-Ruder Y, Seger R, Fainzilber M. Vimentin-dependent spatial translocation of an activated MAP kinase in injured nerve. Neuron. 2005;45:715726.

44 Reynolds AJ, Hendry IA, Bartlett SE. Anterograde and retrograde transport of active extracellular signal-related kinase 1 (ERK1) in the ligated rat sciatic nerve. Neuroscience. 2001; 105:761-771.

45 Manes T, Zheng DQ, Tognin S, Woodard AS, Marchisio PC, Languino LR. Alpha(v)beta3 integrin expression up-regulates cdc2, which modulates cell migration. J Cell Biol. 2003;161: 817-826.

46 Schwartz M, Yoles E. Immune-based therapy for spinal cord repair: autologous macrophages and beyond. J Neurotrauma. 2006;23:360-370.

47 Ziv Y, Ron N, Butovsky O, Landa G, Sudai E, Greenberg N, et al. Immune cells contribute to the maintenance of neurogenesis and spatial learning abilities in adulthood. Nat Neurosci. 2006;9:268-275. 